\title{
Gym Routine Infection Prevention program - An Innovative, Collaborative Approach towards Excellence
}

\author{
Kishori Naik, BSc, CIC; ${ }^{1}$ Eric Moir; ${ }^{2}$ Esther Rupnarain, BA,RN,CIC; ${ }^{1}$ Sandina Noble, BScN, RN,CIC ${ }^{1}$ \\ ${ }^{1}$ West Park Healthcare Centre, Toronto. ON, Canada \\ ${ }^{2}$ Trent University, Peterborough, ON, Canada
}

Corresponding author:

Kishori Naik, BSc, CIC, Infection Prevention and Control Practitioner, West Park Healthcare Centre, Toronto, ON, Canada

Tel.: 416-243-3600 ext.2721 | kishori.naik@westpark.org

\begin{abstract}
Gym Routine Infection Prevention program's (G.R.I.P.) purpose was to establish a monitoring program for hand hygiene and equipment disinfection in six rehabilitation/ complex continuing care gymnasiums. Our goal was to create a safe environment by preventing acquisition of healthcare associated infections (HAIs) by promotion of infection prevention and control (IPAC) best practices with a focus on hand hygiene compliance and the cleaning and disinfection of shared equipment.

A customized tool was created that revealed hand hygiene compliance was $76 \%$ before patient contact and $96 \%$ after patient contact and cleaning shared equipment before patient use was $79 \%$ and after use was $90 \%$.
\end{abstract}

\section{KEYWORDS}

Gym; infection; hand hygiene; equipment cleaning; audit; education; result

\section{INTRODUCTION}

Hospitalized patients are vulnerable to infections due to their clinical conditions and possible immunocompromised state. The Canadian Patient Safety Institute reports that 8,000 Canadians die from hospital-acquired infections each year and a further 200,000 patients become infected with hospital-acquired infections each year [1]. Gymnasiums in rehabilitation centres are settings that pose a potential risk for spread of infections like Staphylococcus sp. and Giardia sp. [2-5]. A study done in a US metropolitan Public Fitness Centre (Mukherjee et al, 2014) showed that the surface swab samples collected from the exercise equipment (stationary bike, hand rails, toilet handles) identified the most prevalent bacterial species as Staphylococcus sp [5]. The possible contributing factors for this include the use of shared equipment such as parallel bars, treadmills, and small sets of stairs with hand railings, which could be reservoirs for microorganisms, a patient's vulnerable health status, the need for more frequent hands-on care for this specific population undergoing rehabilitation from rehab assistants and a fastpaced working environment.

There has been no baseline data of compliance of either hand hygiene or equipment disinfection in the gym of our facility. An innovative approach was adopted to use a customized audit tool. The results of the audits were intended to identify any barriers and improve these practices.

\section{METHODS}

The rehabilitation/complex continuing care (rehab/CCC) facility is located in Toronto, Ontario, Canada with 276 inpatient beds, as well as outpatients who come to the facility for rehab. The patient population consisted of individuals requiring rehab due to the loss of a limb, stroke, spinal cord injury, chronic obstructive pulmonary disease (COPD), or other physical injuries. Each of the six gyms audited had unique patient groups that accessed them. The largest gym at this rehab/CCC, the amputee gym, had a mix of inpatients and outpatients the majority of which were young adults to middle aged, and they used recombinant bikes, parallel bars, treadmills and beds for practicing movement in bed and standing and sitting. The neurological gym is the second largest gym at the facility. It contains less workout equipment compared to the amputee gym, but is still larger than the other gyms attached to the various units. The gym included parallel bars, some cardio equipment, but also many puzzles, small items for fine motor manipulation, open space for patients to re-master ambulation, and beds for patients to practice skills.

As there was no available standardized tool to perform audits in a gym setting, a customized tool was created to monitor compliance of hand hygiene and equipment disinfection by gymnasium staff. This staff was comprised of physiotherapists, occupational therapists, rehabilitation assistants, environmental services, nurses and other staff. Cleaning and disinfection of equipment includes wiping high-touched areas and drying time.

Acknowledgements: The authors would like to acknowledge Sumana Vinod MBBS,MPH,CIC (Infection Control Professional), Aurora Wilson RN, BScN, MN, CIC (Manager, Infection Prevention and Control at Providence Healthcare) Murtuza Diwan, BSc (Hons), MSc, CIC (Infection Control Professional Infection Prevention and Control, Halton Healthcare), Janet Mulgrave (Service Manager, West Park Healthcare Centre), and the allied health staff at West Park Healthcare Centre for their contributions to this manuscript.

Conflicts of interest: None. 
The process of developing the tool involved gathering ideas from 20 gymnasium staff through in-person interviews and input through e-mails, which included current perception of hand hygiene practices and the idea of using a customized tool to monitor hand hygiene and equipment disinfection in gyms. The tool was developed to capture data related to staff hand hygiene and equipment cleaning compliance rate. The tool was then sent out to staff to gather their opinions.

Feedback from potential users of the tool was gathered and the tool modified to better suit this healthcare setting. A fourth-year Bachelor of Science in Nursing student and IPAC attended meetings to get direct feedback on the tool and began auditing the first week of February 2019. Staff were asked whether they felt they were performing hand hygiene using alcohol-based hand sanitizer (ABHS) and cleaning equipment often enough to reduce the risk of infection. Staff were also asked if they believed patients were performing hand hygiene often enough to reduce the spread of infectious organisms. The student carried out direct observations of patients and gym staff in six gyms over a four-week period. The audits, which were conducted during the standard hours of operation during the day, involved repeated observation of staff by the student with the support of IPAC staff. Over the same time period, staff meetings were held to share real-time compliance data and gather feedback about the tool, which was used to modify it.

The audit tool was initially based on the Just Clean Your Hands (JCYH) program developed by Public Health Ontario as a trial for observations ${ }^{6}$. After observations were carried out and feedback was gathered from staff, this tool was modified to better suit the gym environment (Figure 1). The JCYH tool has the first moment involving contact with patient or patient's environment. The modified tool identified moments to suit the gym activity and separated the first moment into contact with patient and patient's environment meaning equipment. Further, this tool was classified into two sections: required and recommended. Recommended moments were monitored but not taken into consideration when adherence rates were tallied as they may not always be feasible e.g. limited mobility of the hands of a patient. Since we do not have baseline data, our target was to achieve $80 \%$ of overall compliance.

\section{Required moments include:}

- Staff performing hand hygiene before patient contact

- Staff performing hand hygiene after patient contact

- Staff disinfecting equipment before patient use

- Staff disinfecting equipment after patient use

\section{Recommended moments include:}

- Staff performing hand hygiene when they enter and exit a gym

- Staff encouraging patients to perform hand hygiene before entering and upon exiting the gym

- Staff encouraging patients to perform hand hygiene before and after activities.
The Education tool (Appendix A) (6,7,8 $^{6}$ was developed as an important element of this improvement program. The Infection Control Practitioner, assisted by the student of this project, imparted education sessions to staff and the tool was also posted in the gyms as a visual reminder. The tool included background information on hospital-acquired infections and why hand hygiene and equipment decontamination are important. While handing out this resource IPAC/student answered staff questions, gathered feedback on the hand-out and provided on-the-spot education on hand hygiene and equipment decontamination. A power point presentation on G.R.I.P. was also created that detailed the project, specifically mentioning the project's goal, background, hand hygiene and equipment decontamination, adherence rates and conclusions. A project overview was sent to the team leads of each gym that was audited.

\section{RESULTS}

Patient hand hygiene compliance was monitored, but has not been included in the results. A total of 259 observations were made across six gyms between the beginning of February 2019 and the first week of April 2019. In the 2-East Functional Enhancement gym, 25 observations of rehab assistants were carried out, and two physiotherapist observations for a total of 27 observations. Staff observations in the 3-East Musculoskeletal gym consisted of 40 observations of rehab assistants and one observation of a physiotherapist totaling 41 observations. Fourteen observations of rehab assistants in the 2-West Respiratory gym were conducted and 30 observations of physiotherapists totaling 44 observations. In the 3-West Adult Disability/Multiple Sclerosis (MS) gym 52 observations of rehab assistants were conducted and 14 observations of physiotherapist for a total of 66 observations.

For the Neurological gym, 17 observations of rehab assistants were conducted, 13 observations of physiotherapists, two observations of occupational therapists, and two observations of two other staff members for a total of 34 observations. The patients in the Neurological gym have a higher acuity of care, therefore, the length of time spent on a patient was longer which explains the number of audits to the observations made. For the Amputee gym, 27 observations of rehab assistants were carried out, and 20 observations of physiotherapists for a total of 47 observations. Average hand hygiene and all the gyms and healthcare staff before patient contact was $76 \%$; after-patient contact was $96 \%$; equipment disinfection before patient use was $79 \%$; and $90 \%$ after patient use (Table 1 ).

\section{DISCUSSION}

In the gym environment, some barriers to infection control practices were identified by staff such as working in a fastpaced environment, varied staff to patient ratios, and the kind of equipment that patients use. Furthermore, staff members were concerned that G.R.I.P. could interfere with their ability to carry out their duties within their scheduled work shift. Despite the development of the tool, limitations to compliance to best practices exist. Staff-to-patient ratios vary across the hospital and as such, depending on the gym staff are working in, it can 


\begin{tabular}{|l|c|c|c|c|}
\hline TABLE 1: Audit moments observed divided by gym in which observation occurred. \\
\hline Gym audited & $\begin{array}{c}\text { Hand hygiene before } \\
\text { patient contact }\end{array}$ & $\begin{array}{c}\text { Hand hygiene after } \\
\text { patient contact }\end{array}$ & $\begin{array}{c}\text { Cleaning equipment } \\
\text { before patient use }\end{array}$ & $\begin{array}{c}\text { Cleaning equipment } \\
\text { after patient use }\end{array}$ \\
\hline 2-East (Functional Enhancement) & $9 / 11(82 \%)$ & $10 / 10(100 \%)$ & $1 / 1(100 \%)$ & $10 / 10(100 \%)$ \\
\hline 3-East (Musculoskeletal) & $17 / 23(74 \%)$ & $8 / 8(100 \%)$ & $7 / 7(100 \%)$ & $11 / 13(85 \%)$ \\
\hline 3-East (Amputee) & $14 / 15(93 \%)$ & $18 / 20(90 \%)$ & $4 / 8(50 \%)$ & $13 / 15(87 \%)$ \\
\hline 3-East (Neurological) & $9 / 11(82 \%)$ & $14 / 15(93 \%)$ & $2 / 2(100 \%)$ & $14 / 16(88 \%)$ \\
\hline 2-West (Respiratory) & $13 / 15(87 \%)$ & $25 / 25(100 \%)$ & No observations made & $7 / 8(88 \%)$ \\
\hline 3-West (Adult disability/MS) & $21 / 34(62 \%)$ & $28 / 29(97 \%)$ & $1 / 1(100 \%)$ & $17 / 18(94 \%)$ \\
\hline Hospital average & $83 / 109(76 \%)$ & $93 / 97(96 \%)$ & $15 / 19(79 \%)$ & $72 / 80(90 \%)$ \\
\hline
\end{tabular}

be difficult for them to work with multiple patients while still performing equipment disinfection.

The staff-to-patient ratio in the 3-West gym varied from one to seven patients (Hand Hygiene before contact 62\%) whereas staff in the amputee gym may work with one to two patients at a time (hand hygiene before contact 93\%). This suggests higher staff-topatient ratios are associated with better hand hygiene compliance before contact with patient. The $3 \mathrm{~W}$ gym handles MS patients, which entails more care due to greater mobility issues compared to other patients, which possibly adds more work volume to staff. Some equipment have uneven surfaces and may require additional time to disinfect. Wall-mounted wipes are not always positioned in convenient locations and as such may be contributing to less than perfect equipment disinfection. Patients do not always follow staff directions when asked to perform hand hygiene. Due to muscle weakness, patients are not always capable of using the wall-mounted, alcohol-based hand rub (ABHR) dispensers as they require a certain amount of strength and coordination to operate, which in turn may skew audits and therefore patient audits have not been included in the results. Possible solutions to these barriers could include procurement of ABHR dispensers that are activated by a sensor making it easier for patients to use. Emphasis on routine IPAC practices during staff orientation to encourage adherence to appropriate hand hygiene and equipment disinfection practices and the availability of disinfectant wipes at convenient locations may also improve compliance ${ }^{9}$. Moving forward, auditing by Hand Hygiene Champions will enable monitoring of compliance and identify the necessary resources needed for improvements, or additional resources such has staffing, supplies of ABHR and disinfectant wipes.

The purpose of the project was to develop an audit tool that is specific to the rehab gym environment. Our healthcare centre already has a hand-hygiene-monitoring program in place in the patient environment; G.R.I.P. does not replace this program, its purpose is to augment it. On average, hand hygiene and shared equipment cleaning and disinfection adherence rates are above $80 \%$, which is comparable to other areas in the facility. There is room for improvement when staff perform hand hygiene before patient contact. The compliance rates G.R.I.P. captures is for internal reporting only, and only applies specifically to the gym environment. Data is not shared with the Ministry of Health and Long-term Care.

\section{CONCLUSION}

This initiative enabled our facility to identify room for improvement and a plan to sustain higher compliance. Our plan moving forward is to train auditors to perform 30-50 observations per gym every three to four months and then evaluate the data collected. From there the project may be expanded so gyms are audited each quarter and the results sent to leadership and routinely posted in the gyms audited.

\section{REFERENCES}

1. Canadian Patient Safety Institute. (2016) Health Care Associated Infections. Retrieved from: https://www.patientsafetyinstitute.ca/en/ Topic/Pages/Healthcare-Associated-Infections-(HAI).aspx.

2. Markley, J.D., Edmond, M.B., Major, Y., Bearman, G., Stevens, M.P. (2012). Are Gym Surfaces Reservoirs for Staphylococcus aureus? A point prevalence survey. American Journal of Infection Control, 40(10), 1008-1009. DOI:10.1016/j.ajic.2012.01.015.

3. Maurice Bilung, L., Tahar, A.S., Kira, R., Mohd Rozali, A.A., Apun, K. (2018). High Occurrence of Staphylococcus aureus Isolated from Fitness Equipment from Selected Gymnasiums. Journal of Environmental Public Health. DOI:10.1155/2018/4592830.

4. Los Angeles County Department of Public Health Acute Communicable Disease Control Special Reports (2005). Giardiasis Outbreak Associated with a Women's Gym. Retrieved from: http://publichealth.lacounty.gov/ Acd/pubs/reports/spclrpts/spcrpt05/GiardiaOutbreak05.pdf

5. Mukherjee, N., Dowd, S.E., Wise, A., Kedia, S., Vohra, V., Banerjee, P. (2014). Diversity of Bacterial Communities of Fitness Center Surfaces in a U.S. Metropolitan Area. International Journal of Environmental Research and Public Health, 11(12),12544-12561. DOI:10.3390/ijerph111212544.

6. Ontario Ministry of Health and Long Term Care. (December 2011). 'Just Clean Your Hands'. Retrieved from: https://www.publichealthontario.ca/en/health-topics/infection-prevention-control/handhygiene/jcyh-hospitals.

7. Ontario Agency for Health Protection and Promotion (Public Health Ontario), Provincial Infectious Diseases Advisory Committee. Best Practices for Hand Hygiene in All Health Care Settings. 4th ed. Toronto, ON: Queen's Printer for Ontario; January 2014.

8. Ontario Agency for Health Protection and Promotion (Public Health Ontario), Provincial Infectious Diseases Advisory Committee. Best practices for environmental cleaning for prevention and control of infections in all health care settings. 3rd ed. Toronto, ON: Queen's Printer for Ontario; 2018.

9. Elba, I., Ivy, J.W. (2018). Increasing the Post-Use Cleaning of Gym Equipment Using Prompts and Increased Access to Cleaning Materials. Behavior Analysis in Practice. 11(4),390-394. DOI:10.1007/ s40617-018-0217-0. 
FIGURE 1: Customized audit tool

\section{G.R.I.P: Gym Routine Infection Prevention Program}

Form \#:

Gym:

Date:

Start Time:

End Time:

Required Best Practice

Pro

West Park get
FOUNDATION
your
life
back

\begin{tabular}{|l|l|l|l|l|l|}
\hline HCP category \# & \multicolumn{3}{|l|}{} & HCP category \# & \\
\hline BEF PAT & Yes $\square$ No $\square$ & BEF PAT & Yes $\square$ No $\square$ \\
\hline AFT PAT & Yes $\square$ No $\square$ & AFT PAT & Yes $\square$ No $\square$ \\
\hline WIPE BEF PAT USE & Yes $\square$ No $\square$ & WIPE BEF PAT USE & Yes $\square$ No $\square$ \\
\hline WIPE AFT PAT USE & Yes $\square$ No $\square$ & WIPE AFT PAT USE & Yes $\square$ No $\square$ \\
\hline
\end{tabular}

Recommended Hygiene

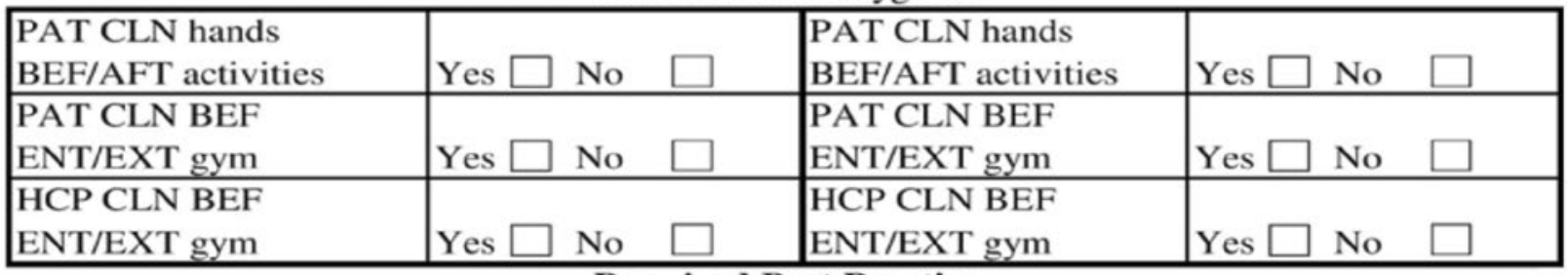

\begin{tabular}{|l|l|l|l|l|}
\hline HCP category \# & \multicolumn{3}{|l|}{ HCP category \# } & \\
\hline BEF PAT & Yes $\square$ No $\square$ & BEF PAT & Yes $\square$ No $\square$ \\
\hline AFT PAT & Yes $\square$ No $\square$ & AFT PAT & Yes $\square$ No $\square$ \\
\hline WIPE BEF PAT USE & Yes $\square$ No $\square$ & WIPE BEF PAT USE & Yes $\square$ No $\square$ \\
\hline WIPE AFT PAT USE & Yes $\square$ No $\square$ & WIPE AFT PAT USE & Yes $\square$ No $\square$ \\
\hline
\end{tabular}

Recommended Hygiene

\begin{tabular}{|l|l|l|l|}
\hline $\begin{array}{l}\text { PAT CLN hands } \\
\text { BEF/AFT activities }\end{array}$ & Yes $\square$ No $\square$ & $\begin{array}{l}\text { PAT CLN hands } \\
\text { BEF/AFT activities }\end{array}$ & Yes $\square$ No $\square$ \\
\hline $\begin{array}{l}\text { PAT CLN BEF } \\
\text { ENT/EXT gym }\end{array}$ & Yes $\square$ No $\square$ & $\begin{array}{l}\text { PAT CLN BEF } \\
\text { ENT/EXT gym }\end{array}$ & Yes $\square$ No $\square$ \\
\hline HCP CLN BEF & Yes $\square$ No $\square$ & $\begin{array}{l}\text { HCP CLN BEF } \\
\text { ENT/EXT gym }\end{array}$ & Yes $\square$ No $\square$ \\
\hline
\end{tabular}

Required Best Practice

\begin{tabular}{|l|l|l|l|l|}
\hline HCP category \# & \multicolumn{3}{|l|}{} & HCP category \# \\
\hline BEF PAT & Yes $\square$ No $\square$ & BEF PAT & Yes $\square$ No $\square$ \\
\hline AFT PAT & Yes $\square$ No $\square$ & AFT PAT & Yes $\square$ No $\square$ \\
\hline WIPE BEF PAT USE & Yes $\square$ No $\square$ & WIPE BEF PAT USE & Yes $\square$ No $\square$ \\
\hline WIPE AFT PAT USE & Yes $\square$ No $\square$ & WIPE AFT PAT USE & Yes $\square$ No $\square$ \\
\hline
\end{tabular}

Recommended Hygiene

\begin{tabular}{|l|l|l|l|}
\hline PAT CLN hands & PAT CLN hands & \\
BEF/AFT activities & Yes $\square$ No $\square$ & BEF/AFT activities & Yes $\square$ No $\square$ \\
\hline $\begin{array}{l}\text { PAT CLN BEF } \\
\text { ENT/EXT gym }\end{array}$ & Yes $\square$ No $\square$ & $\begin{array}{l}\text { PAT CLN BEF } \\
\text { ENT/EXT gym }\end{array}$ & Yes $\square$ No $\square$ \\
\hline HCP CLN BEF & Yes CLN BEF \\
ENT/EXT gym & Ye $\square$ No $\square$ & $\begin{array}{l}\text { ENT/EXT gym } \\
\text { ENT }\end{array}$ & Yes $\square$ No $\square$ \\
\hline
\end{tabular}




\section{FIGURE 1a: Instructions to the auditor}

- If using the paper copy of this tool, write the HCP category number into the box next to 'HCP category \#'.

- Check the Yes box if the HCP being audited is observed performing the moment, if the moment is missed tick the No box.

- Auditors should choose one HCP, approach them and determine their HCP category and then observe them with one patient and observe the HCP as they move onto the next patient to get a complete observation.

- The auditor should not interfere with the HCP's work and must leave if asked to do so.

\section{Healthcare Providers (HCP) categories}

1 = Rehabilitation Assistant, 2 = Physiotherapist

3 = Occupational Therapist, $4=$ Nurse

$5=$ Environmental Services, $6=$ Other Staff

\section{Moments for Hand Hygiene and Equipment Decontamination}

- BEF PAT refers to the HCP performing hand hygiene before coming into physical contact with the patient.

- AFT PAT refers to the HCP performing hand hygiene after coming into physical contact with the patient.

- WIPE BEF PAT USE refers to the HCP performing decontamination of frequent touch points with a disinfecting wipe before the patient uses the equipment.

- WIPE T PAT USE refers to the HCP performing decontamination of frequent touch points with a disinfecting wipe after the patient uses the equipment.

- $\mathrm{PAT}$ CLN hands BEF/AFT activities refer to whether the HCP encouraged the patient to perform hand hygiene before and after activities in the gym.

- PAT CLN BEF ENT/EXT gym refers to whether the HCP encouraged the patient to perform hand hygiene before entering and upon exiting the gym.

- HCP CLN BEF ENT/EXT gym refers to whether the HCP performed hand hygiene before entering and upon exiting the gym. 